\title{
The baboon: a model for the study of primate growth hormone receptor gene expression during development
}

\section{G Zogopoulos ${ }^{1,2}$, P Nathanielsz ${ }^{5}$, G N Hendy ${ }^{2,3,4}$ and C G Goodyer ${ }^{1,2}$}

\author{
${ }^{1}$ Department of Pediatrics, McGill University, Montreal, Québec, Canada \\ ${ }^{2}$ Department of Medicine, McGill University, Montreal, Québec, Canada \\ ${ }^{3}$ Department of Physiology, McGill University, Montreal, Québec, Canada \\ ${ }^{4}$ Department of Human Genetics, McGill University, Montreal, Québec, Canada \\ ${ }^{5}$ Department of Physiology and the Laboratory for Pregnancy and Newborn Research, College of \\ Veterinary Medicine, Cornell University, Ithaca, New York, USA \\ (Requests for offprints should be addressed to C G Goodyer, Endocrine Research Laboratory, Room \\ C-1238, McGill University - Montreal Children's Hospital, Research Institute, 2300 Tupper St, \\ Montreal, Québec, Canada H3H 1P3)
}

\begin{abstract}
In subprimates, significant onset of growth hormone receptor (GHR) expression occurs only after birth whereas, in the human, GHR mRNA and protein are widely manifest from the first trimester of fetal life. Thus, it is likely that subprimates are not the best models for studying regulation of human GHR gene transcription, especially during early stages in development. Here we have explored the potential of the baboon as a more appropriate model. Baboon GHR cDNAs were cloned from postnatal liver by reverse transcription (RT)-PCR, using human GHRspecific primers. The encoded baboon GHR precursor protein has an identical signal peptide sequence to that of human and rhesus monkey GHRs, and the mature baboon GHR is also 620 amino acids long, with $95 \%$ and $98.5 \%$ amino acid identity to the human and rhesus monkey receptors respectively. Previous studies in the human have identified eight $5^{\prime}$ untranslated region (5' UTR) variants of the GHR mRNA (V1 to V8, numbered according to their relative abundance). We cloned the baboon V1, V3 and V4 homologues by RT-PCR: these variants have a high degree (>92\%) of sequence identity with their human counterparts
\end{abstract}

and also diverge at an identical point, 12 nucleotides upstream of the start of translation. The expression pattern of these three GHR mRNA isoforms in baboon liver during development was characterized. Strong expression of baboon V1 and V4 was evident by 49 days of postnatal life $(n=5,49$ days and adult $(18 \cdot 6-19 \cdot 6 \mathrm{~kg}))$; very low levels of V1, but not V4, were observed in younger animals $(n=2,6$ and 30 days). In contrast, V3 $5^{\prime}$ UTR variant mRNA was present in all fetal ( $n=4,141-155$ days gestation) and postnatal $(n=7,6-19 \cdot 6$ days and adult $(18 \cdot 6 \mathrm{~kg}))$ hepatic specimens examined. Analysis of postnatal kidney and lung ( $n=2,19$ and $19 \cdot 6 \mathrm{~kg})$ revealed that V3 transcripts are present in these tissues, but not V1 and V4. Together, these data demonstrate that, as in the human, baboon V1 and V4 expression is developmentally regulated and tissue specific, while the V3 isoform is more widely expressed. Therefore, it is likely that the regulatory regions of the baboon and human GHR genes are well conserved. Our findings suggest that the baboon is an appropriate animal model in which to define the mechanisms regulating GHR gene transcription during primate development.

Fournal of Molecular Endocrinology (1999) 23, 67-75

\section{INTRODUCTION}

The growth hormone (GH) receptor (GHR) mediates multiple metabolic as well as growthpromoting effects in skeletal and soft tissues: expression of functional GHRs is essential for normal postnatal mammalian growth and metabolic homeostasis (Rosenbloom et al. 1997). However, the physiological significance of the GHR during fetal development is poorly understood (Gluckman \& Harding 1997, Hay et al. 1997). Ontogenic studies in subprimates (rodent, sheep, cow, rabbit and pig) show that significant onset of GHR mRNA and protein synthesis occurs only after birth (Walker 
et al. 1992, Ymer \& Herington 1992, Breier et al. 1994, Schnoebelen-Combes et al. 1996). In contrast, we have demonstrated that, in the human, GHR mRNA is widely expressed from the first trimester of fetal life (Zogopoulos et al. 1996a). In addition, GHR immunostaining has been identified in human tissues as early as 8.5 weeks of fetal age; by midgestation, the tissue distribution of the GHR is often identical to that found in the adult (Hill et al. 1992, Simard et al. 1996). Thus, significant GHR mRNA and protein synthesis begins earlier in human development than in lower species, indicating an important role for the GHR during human fetal growth.

The diversity of the $5^{\prime}$ untranslated region $\left(5^{\prime}\right.$ UTR) of GHR mRNA in the human (Pekhletsky et al. 1992, Zogopoulos et al. 1997), ovine (O’Mahoney et al. 1994, Adams 1995), bovine (Heap et al. 1995) and rodent (Baumbach \& Bingham 1995, Menon et al. 1995) has suggested that, in all species, multiple promoter regions may regulate transcription of the GHR gene. In the human, eight different 5' UTR variants, numbered V1 to V8 according to their relative abundance, have been cloned from adult liver by $5^{\prime}$ rapid amplification of cDNA ends (5' RACE) (Pekhletsky et al. 1992). All eight variants have distinct nucleotide sequences and only converge at -11 nucleotides prior to the start site of translation in exon 2. We have recently demonstrated that expression of two of these variants is tissue specific as well as developmentally regulated: V1 and V4 were only detected in postnatal liver (Zogopoulos et al. 1996b, 1997). In contrast, V3 GHR mRNA transcripts were present in all human tissues examined, from as early as 10 weeks of fetal age (Zogopoulos et al. 1996b, 1997). Induction of V1 and V4 expression in postnatal liver appears to be functionally significant: there is, in parallel, a 4-fold increase in total hepatic GHR mRNA levels as well as GHR receptor binding activity (Zogopoulos et al. 1997, 1998). Our subsequent studies have mapped the V1 and V4 sequences to the same region in the human GHR gene and revealed that their transcription is regulated by a common promoter (Zogopoulos et al. 1998). The V3 sequence has been localized to a distinct genomic region and preliminary studies suggest that it is transcribed from a unique start site ( $\mathrm{G}$ Zogopoulos, C G Goodyer and G N Hendy, unpublished data). Together, these data suggest an important developmental switch in GHR gene expression due to differential promoter usage.

The finding of earlier GHR expression in the human than in subprimates (Hill et al. 1992, Walker et al. 1992, Ymer \& Herington 1992, Breier et al. 1994, Schnoebelen-Combes et al. 1996, Simard et al. 1996, Zogopoulos et al. 1996a) suggests that these lower species are not the best models for studying regulation of the human GHR gene during fetal and early postnatal life, and that another primate may be more appropriate. In the present study, human GHR-specific primers were used to clone baboon GHR cDNAs by reverse transcription (RT)-PCR from postnatal baboon liver total RNA. Nucleotide sequencing of multiple clones revealed that the baboon GHR has a high level of sequence identity with the human (95\%) and rhesus monkey (98.5\%) GHRs (present data, Leung et al. 1987, Martini et al. 1997). V1, V3 and V4 homologues were also cloned by RT-PCR from postnatal baboon liver. Subsequent semi-quantitative RTPCR and Southern blotting analysis showed that, as in the human, baboon V1 and V4 GHR mRNA expression is developmentally regulated and tissue specific, whereas V3 is widely expressed in fetal and postnatal tissues. Therefore, it is likely that the regulatory regions in the baboon and human GHR genes are well conserved, resulting in similar GHR mRNA regulation in the two species. These data suggest that the baboon is an appropriate animal model in which to study GHR mRNA expression during primate development.

\section{MATERIALS AND METHODS}

\section{Tissues}

Fetal and postnatal baboon tissues were obtained immediately after the animals were killed $(n=8,141$ days gestation to adult; term $=\sim 184$ days). Those animals that were wild caught have been identified by weight at the time of study since their ages were unknown. The human postnatal liver specimen (transplant donor age $=43$ years) was collected $5 \mathrm{~h}$ following death. Specimens were flash-frozen in dry-ice acetone and stored at $-70{ }^{\circ} \mathrm{C}$ for RNA extraction. Total RNA was isolated using the guanidine thiocyanate/ $\mathrm{CsCl}$ gradient method, and treated with deoxyribonuclease I (DNAse I; Amersham Pharmacia Biotech, Baie d'Urfé, Quebec, Canada) to eliminate genomic DNA contamination. Animal protocols were approved by the Cornell University Institutional Animal Care and Use Committee; animal facilities were approved by the American Association for the Accreditation of Laboratory Animal Care.

\section{RT-PCR cloning of baboon GHR cDNAs}

Five micrograms postnatal (49 days) baboon liver total RNA were reverse transcribed for $1 \mathrm{~h}$ at $48^{\circ} \mathrm{C}$ with $0.6 \mu \mathrm{M}$ of the appropriate antisense human 
TABLE 1. Sequence of the oligonucleotide RT-PCR primers and the internal hybridization probe $(*)$

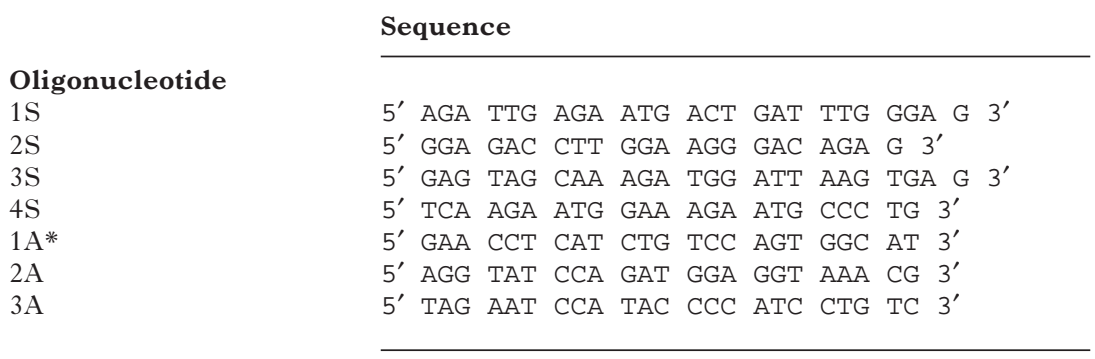

GHR primer (Table 1 and Fig. 1), as previously described (Zogopoulos et al. 1996b). Parallel RT reactions were run in the absence of AMV-RT to ascertain that gene transcripts and not genomic DNA were being amplified. Six microlitres RT product were amplified for 30 cycles in $0.3 \mu \mathrm{M}$ of the appropriate sense and antisense human GHR primers (Table 1 and Fig. 1), $0.5 \mathrm{mM}$ deoxyribonucleotides (dNTPs; Amersham Pharmacia Biotech), $22.5 \mathrm{mM} \mathrm{MgCl}_{2}, 2.5 \mathrm{U}$ Taq/PWO polymerase mix (Roche Diagnostics, Laval, Quebec, Canada), and $1 \times$ Expand Long Template PCR System Buffer \#3 (Roche Diagnostics). The reaction was heated at $92{ }^{\circ} \mathrm{C}$ for $2 \mathrm{~min}$, cycled 30 times for $10 \mathrm{~s}$ at $92{ }^{\circ} \mathrm{C}, 30 \mathrm{~s}$ at $61{ }^{\circ} \mathrm{C}$ and $2 \mathrm{~min}$ at $68^{\circ} \mathrm{C}$, and terminated with a final elongation of 5 min at $68^{\circ} \mathrm{C}$. The amplified cDNAs were inserted into the PGEM-T TA cloning vector (Promega, Madison, WI, USA) and three independent clones were sequenced using a Li-Cor automated system (Li-Cor Biotech, Lincoln, NE, USA).

\section{Semi-quantitative RT-PCR}

RT reactions were carried out as described above and $6 \mu \mathrm{l}$ RT product were amplified for 25 cycles
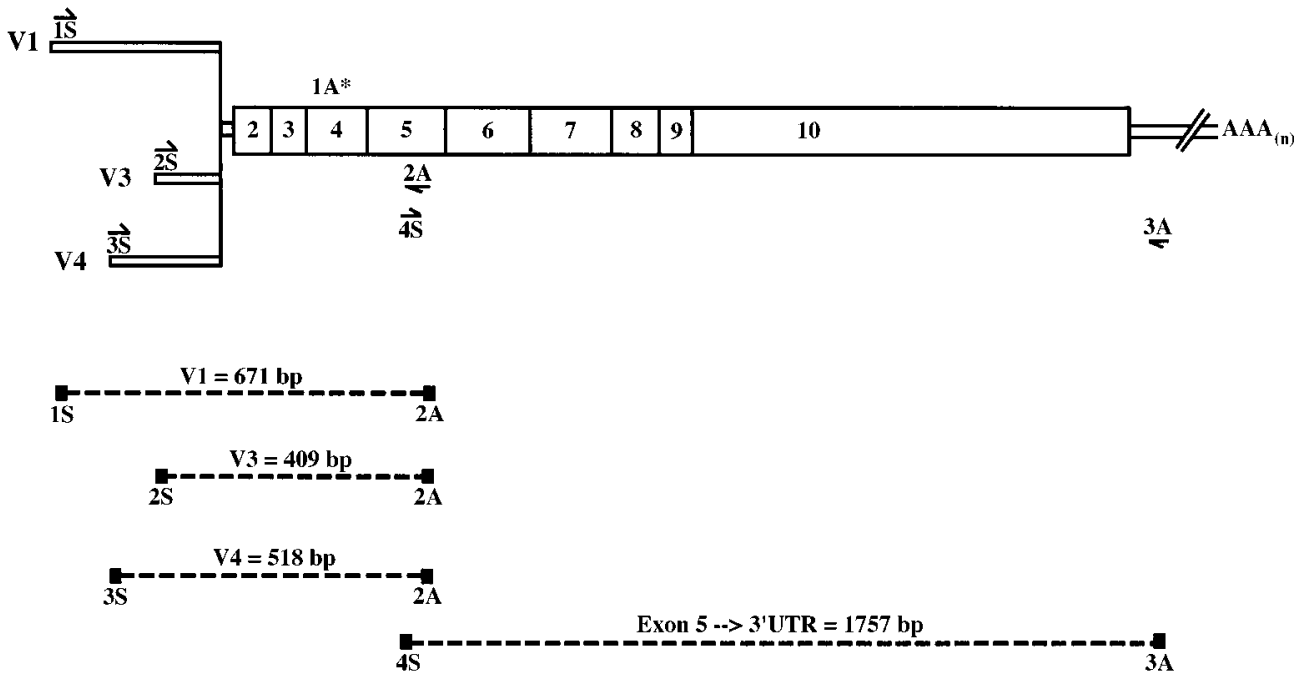

FIGURE 1. Schematic representation of homologous baboon and human cDNA isoforms. Coding exons are indicated by numbered boxes and 5' UTRs are represented by empty boxes. The relative positions of the sense (S) and antisense (A) primers as well as the internal hybridization probe $\left(1 \mathrm{~A}^{*}\right)$ are indicated (oligonucleotide sequences are provided in Table 1). Total RNA was reverse transcribed with primer $2 \mathrm{~A}$, and primer sets $1 \mathrm{~S} / 2 \mathrm{~A}, 2 \mathrm{~S} / 2 \mathrm{~A}$ and $3 \mathrm{~S} / 2 \mathrm{~A}$ were used specifically to amplify the V1, V3 and V4 cDNAs respectively. The remaining baboon cDNA coding region was cloned using primer $3 \mathrm{~A}$ in the RT step, and the 4S/3A PCR primer combination. Broken lower lines indicate the resulting PCR products after amplification with these sets of primers. The V1 and V4 internal standards, used as positive controls in the semi-quantitative RT-PCR assays, both generate PCR products of $382 \mathrm{bp}$. 
with $0 \cdot 25 \mu \mathrm{M}$ human GHR sense and antisense primers (Table 1 and Fig. 1), as previously described (Zogopoulos et al. 1996b). Internal V1 and V4 standards were generated using the PCR method of Jin et al. (1994); a V3 standard could not be used since multiple (V3a, V3b, V3c) variant transcripts have been described for the human GHR (Pekhletsky et al. 1992). Under the specified conditions, each amplification reaction was still in the exponential phase.

\section{Southern blotting analysis of PCR products}

PCR products were resolved on 2\% agarose gels and transferred to $0.45 \mu \mathrm{m}$ positively charged nylon membranes (Schleicher \& Schuell, Keene, NH, USA). Blots were hybridized, using $0.4 \mathrm{nCi} / \mathrm{ml}$ end-labelled probe (Table 1 and Fig. 1) per $\mathrm{cm}^{2}$ nylon membrane, as previously described (Zogopoulos et al. 1996b). Bands were visualized by autoradiography following $3-14 \mathrm{~h}$ exposure to Kodak XAR-5 film (Eastman Kodak) using two intensifying screens.

\section{RESULTS}

\section{Cloning of GHR cDNAs from baboon liver}

To determine if, in the baboon, V1, V3 and V4 GHR mRNAs showed the same developmental patterns of expression as in the human, we used human-specific primers and the RT-PCR strategy described in Fig. 1 to clone the V1, V3 and V4 baboon cDNA homologues from postnatal liver total RNA. Nucleotide sequencing revealed that, like their human counterparts, the three baboon 5' UTR variants diverge at -12 nucleotides from the start site of translation in exon 2 (Fig. 2). The human (Pekhletsky et al. 1992) and baboon 5' UTR homologues are highly conserved: $96 \%$ for $\mathrm{V} 1$ and $92 \%$ for V4, while the shorter nucleotide stretch of the baboon V3 5' UTR matches its human counterpart precisely. It should be noted that an additional alternatively spliced V3 isoform of longer length and lower abundance has been identified in the human (Pekhletsky et al. 1992, Zogopoulos et al. 1996b). Evidence for the presence of this V3 subvariant in the baboon was obtained following longer exposure of the Southern blots to X-ray film (data not shown). The baboon V1 sequence was also a perfect match for the 5' UTR sequence of the rhesus monkey GHR cDNA reported by Martini et al. (1997) except, surprisingly, for the terminal $3^{\prime} 12$ nucleotides representing the splice site in exon 2 : these were missing in the rhesus monkey GHR mRNA sequence.

To obtain the complete baboon GHR mRNA coding sequence, a second RT-PCR, using humanspecific primers within exon 5 and the $3^{\prime}$ UTR, was carried out. The complete nucleotide sequence of the baboon GHR cDNA predicts a 620 amino acid mature protein, with $95 \%$ and $98.5 \%$ amino acid sequence similarity with the human (Leung et al. 1987) and rhesus monkey receptors (Martini et al. 1997) respectively (Fig. 3). The characteristic features of the GHR are all well conserved in the three primates: the 18 amino acid signal peptide, the seven cysteine residues, five potential N-glycosylation sites and YGEFS motif of the extracellular domain, and the proline-rich Box 1 region of the cytoplasmic tail (Fig. 3) (Argetsinger \& Carter-Su 1996).

\section{Characterization of V1, V3 and V4 mRNA expression during development}

The RT-PCR/Southern blot strategy used to characterize V1, V3 and V4 mRNA expression is summarized in Fig. 1. In each analysis, aliquots from the same RT reaction were tested for expression of each variant. V1 and V4 transcripts were not detectable in the fetal livers examined ( $n=4,141-155$ days gestation), and were only readily identified in hepatic samples at and following 49 days of life $(n=4,49$ days and adult $(18 \cdot 6-19 \cdot 6 \mathrm{~kg})$ ) (Fig. 4). Low levels of V1 were also present in younger postnatal animals $(n=2,6$ and 30 days); V4 mRNAs were not detectable at this early postnatal stage in development. There was no evidence for expression of V1 and V4 transcripts in adult baboon kidney and lung specimens $(n=2,19$ and $19.6 \mathrm{~kg}$ ) (Fig. 4). In contrast to V1 and V4, V3 was observed in all fetal and postnatal baboon livers examined, as well as the postnatal kidney and lung tissues (Fig. 4). Thus, similar to the human (Zogopoulos et al. 1996b, 1997), baboon expression of V1 and V4 GHR mRNA transcripts is developmentally regulated and tissue specific, while the V3 isoform is more widely expressed.

\section{DISCUSSION}

Using human-specific primers, we cloned by RT-PCR the coding exons as well as portions of three 5' UTRs (V1, V3 and V4) of the baboon GHR mRNA. Analysis of the cDNA clones showed that the mature GHR proteins of the baboon and rhesus monkey are extremely well conserved $(98 \cdot 5 \%)$, and have a similar degree of variation from the human 
V1

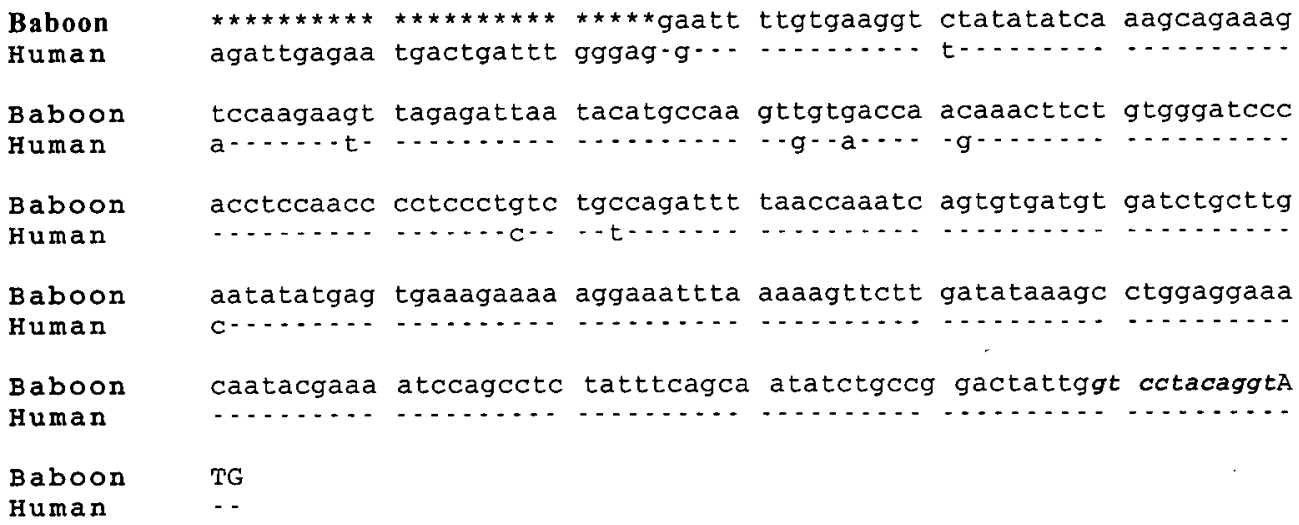

V3

Baboon Human

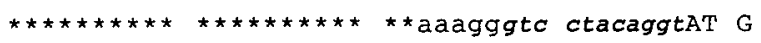
ggagaccttg gaagggacag ag-..............

V4

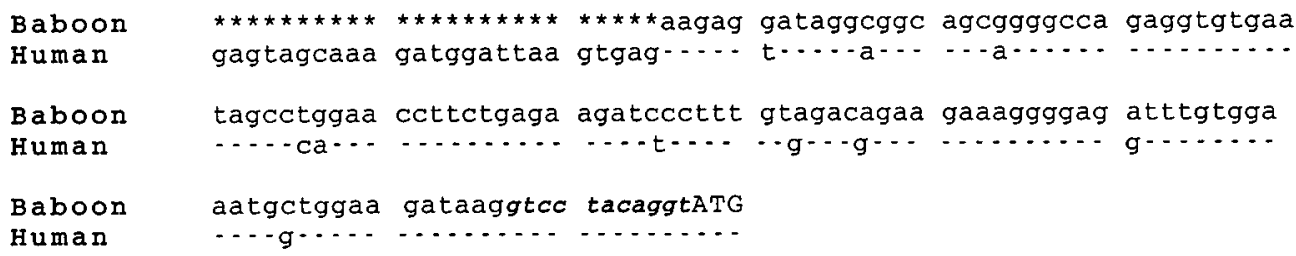

FIGURE 2. Alignment of the baboon V1, V3 and V4 cDNA variants with their human counterparts. Stars indicate baboon nucleotides corresponding to the human-specific GHR primers used to clone the V1, V3 and V4 cDNAs from postnatal baboon liver. Dashes denote common nucleotides. Italicized bold letters identify the 11 nucleotide stretch prior to the ATG start site of translation that is common to the three baboon and human $5^{\prime}$ UTR variants.

(baboon 95\%, rhesus monkey 94\%), with the few amino acid differences dispersed throughout the receptor sequence (present data, Leung et al. 1987, Martini et al. 1997). This is consistent with the idea that these primates are equi-distant evolutionary ancestors of the human (Pausova et al. 1995).

The conserved structural features of the baboon GHR include five potential N-glycosylation sites, seven cysteine residues and the YGEFS motif of the extracellular region, as well as Box 1 of the cytoplasmic domain. Since both the human and rhesus receptors are glycosylated at several sites (Leung et al. 1987, Martini et al. 1997), it is likely that carbohydrate groups are added to the baboon GHR at the conserved asparagine residues. The formation of two extracellular domain disulphide bridges occurs in the GHRs of all species studied to date, and is also a feature of the class I division of the cytokine/GH/prolactin receptor superfamily (Argetsinger \& Carter-Su 1996). Another characteristic of class I receptors is the presence of a WSXWS (where $\mathrm{X}$ is any amino acid) motif in the proximal region of the extracellular domain (Baumgartner et al. 1994, Argetsinger \& Carter-Su 1996). Although this motif is replaced by a related YGEFS consensus in GHRs, the domain is still 
Baboon

Rhesus Monkey

Human

Baboon

Rhesus Monkey

Human

Baboon

Rhesus Monkey

Human

Baboon

Rhesus Monkey

Human

Baboon

Rhesus Monkey

Human

Baboon

Rhesus Monkey

Human

Baboon

Rhesus Monkey

Human

Baboon

Rhesus Monkey

Human

Baboon

Rhesus Monkey

Human

Baboon

Rhesus Monkey

Human

Baboon

Rhesus Monkey

Human

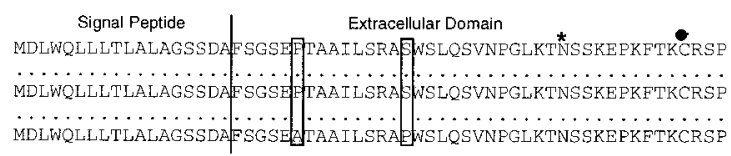

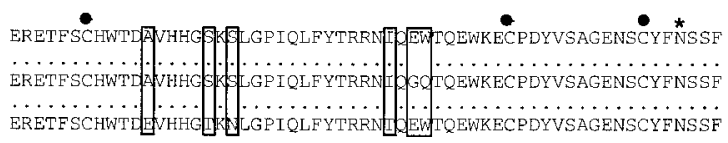

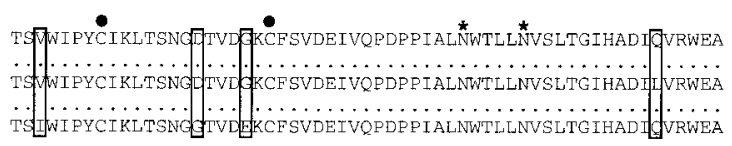

FENADIQKGWMVLEYELQYKEVNETKWKMMDPII

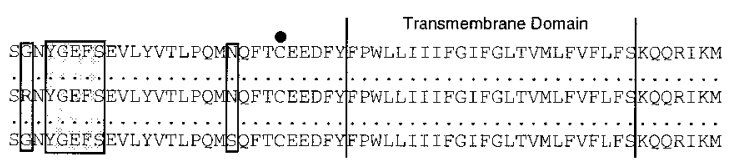

Box 1

Intracellular Domain

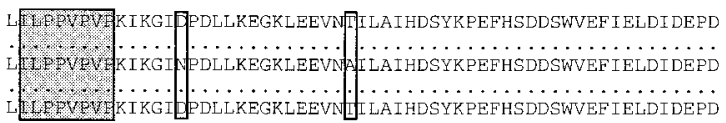

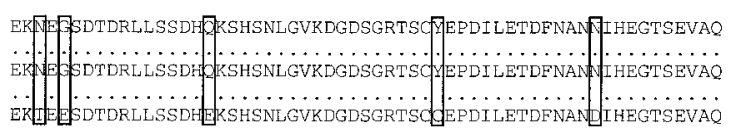

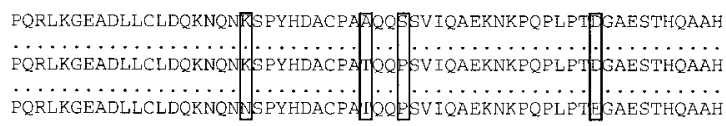

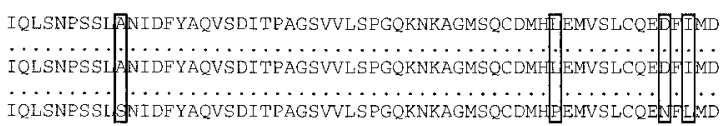

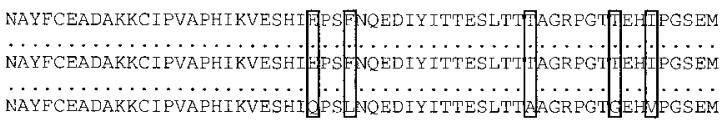

PVPDYTSIHIVQSPQGLILNATALPLARKEELSSCGYVSTDQLNKIMP

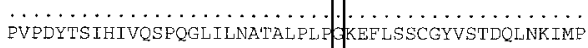

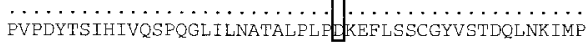

FIGURE 3. Amino acid sequence comparison of the baboon, rhesus monkey and human GHRs. Solid vertical lines mark the boundaries of the signal peptide (18 amino acids) as well as the extracellular (246 amino acids), transmembrane (24 amino acids) and intracellular (350 amino acids) domains. Closed circles and stars identify conserved cysteine residues and $\mathrm{N}$-glycosylation sites respectively. Shaded boxes show the YGEFS and Box 1 motifs. Transparent boxes indicate differences in amino acids among the three species. The absence of an alignment dot between the sequences refers to a residue difference. 

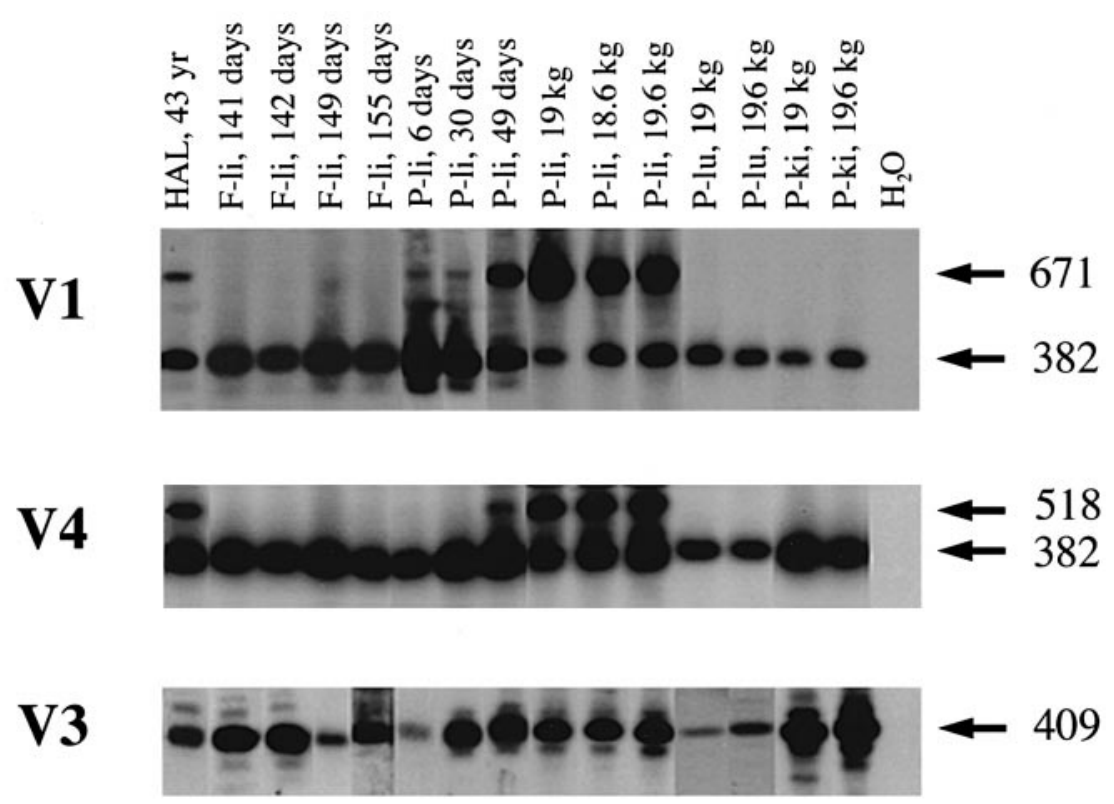

FIGURE 4. Ontogenic and tissue-specific expression of the baboon V1, V4 and V3 5' UTR GHR mRNA variants. Representative Southern blots showing the expression patterns of the GHR mRNA variants in baboon fetal liver (F-li; in days gestation) as well as postnatal liver (P-li; in days or kg), lung (P-lu; in kg) and kidney (P-ki; in kg) tissues. A human liver specimen from a 43 -year-old adult (HAL, 43 yr) was run in parallel. Internal V1 and V4 standards (382 bp) served as a positive amplification control. $\mathrm{H}_{2} \mathrm{O}$ served as a negative RT-PCR control. The sizes of the V1, V4 and V3 PCR products that were cloned and sequenced are indicated (in bp).

required for maximal biological activity of the receptor, probably by directing certain conformational features (Baumgartner et al. 1994, Argetsinger \& Carter-Su 1996). The proline-rich Box 1 domain consists of the same ILPPVPVP consensus sequence in the baboon as in all mammalian GHRs cloned to date. Box 1 is crucial for GHR cellular responses, being responsible for the binding and activation of JAK2 tyrosine kinase, an early event in the intracellular signalling cascades (Wang \& Wood 1995, Argetsinger \& Carter-Su 1996).

Although structural characteristics of the GHR are generally conserved among species, the amino acid sequence identities can be as low as 70\% (Argetsinger \& Carter-Su 1996). The present cloning of the baboon GHR, as well as the recent characterization of the rhesus monkey GHR (Martini et al. 1997), will permit comparative functional studies of primate versus subprimate GHRs. Martini et al. (1997) have already demonstrated an intriguing difference between the monkey and rat GHRs; while the rat GHR binds and activates JAK2 only after $\mathrm{GH}$-induced receptor dimerization, the rhesus monkey receptor is consti- tutively associated with JAK2 even though it only stimulates JAK2 tyrosine kinase activity after ligand binding.

The presence of $5^{\prime}$ UTRs highly conserved between the baboon (present data) and human (Pekhletsky et al. 1992) GHR mRNAs suggests that the GHR gene regulatory regions will be similar in the two primates. The $5^{\prime}$ end of the human GHR gene has recently been characterized: the V1 and V4 5' UTR variants are localized to the same region in the human gene and can be generated (along with V7 and V8) by transcription from a common promoter (Zogopoulos et al. 1998), whereas V3 maps to a distant genomic region and is thought to be regulated by a different promoter (G Zogopoulos, C G Goodyer and G N Hendy, unpublished data). Investigations in subprimates have identified an ovine homologue (exon 1A) to $\mathrm{V} 1$, as well as mouse (L1) and rat (GHR1) transcripts with nucleotide sequences similar to the human V7 variant (Pekhletsky et al. 1992, O'Mahoney et al. 1994, Baumbach \& Bingham 1995, Menon et al. 1995). Ontogenic studies have demonstrated that, like the human or baboon V1 
and V4 isoforms, these subprimate transcripts are present only in postnatal liver (present data, Pekhletsky et al. 1992, O’Mahoney et al. 1994, Baumbach \& Bingham 1995, Menon et al. 1995, Zogopoulos et al. 1996b, 1997). Thus, the $5^{\prime}$ end of the GHR gene regulating postnatal liver-specific GHR mRNA expression in the human appears to be a composite of the homologous ovine and rodent DNA structures. It will be of interest to determine whether the comparable baboon GHR regulatory region is also a composite of the subprimate genomic DNA.

The 5' UTRs of many eukaryotic mRNAs are involved in modulating translation initiation (Jansen et al. 1995). Given that V1 and V4 mRNA expression seems to be restricted to postnatal liver in primates (present data, Zogopoulos et al. 1996b, 1997), it will be important to determine how these two $5^{\prime}$ UTR variants influence translation relative to the widely expressed V3 variant. It is also possible that differential control of fetal versus postnatal tissue expression of the receptor results in distinct $\mathrm{GH}$ biological responses that are critical for normal growth and development. Since these questions will be difficult, if not impossible, to answer directly in the human, especially during fetal and early neonatal stages, the baboon should prove to be a highly useful primate model.

In summary, baboon GHR cDNA isoforms have been cloned by RT-PCR from postnatal liver. The 620 amino acid mature baboon GHR protein is very similar to the human and rhesus monkey receptors. As in the human, expression of the baboon V1 and V4 5' UTR GHR mRNA homologues was found to be developmentally regulated and tissue specific, whereas the V3 isoform was detected in all fetal and postnatal tissues examined. Together, these data suggest that the baboon is an appropriate animal model in which to study GHR gene expression during primate development.

\section{ACKNOWLEDGEMENTS}

The authors would like to thank Dr Jean-Martin Laberge and the operating room staffs at the Montreal Children's and Saint-Justine Hospitals for their support. We also thank Dr Zhou Li (Bio S \& T Inc., Lachine, Quebec, Canada) for his technical assistance in the sequencing of the baboon cDNA isoforms. This work was supported by the McGill University - Montreal Children's Hospital Research Institute (to $\mathrm{C} G \mathrm{G}$ ) and the Claude Giroud Memorial Fund (to $\mathrm{G} \mathrm{Z}$ and $\mathrm{C}$ G G), as well as grants from the Medical Research Council of Canada (to $\mathrm{C} \mathrm{G} \mathrm{G}$ and $\mathrm{G} \mathrm{N} \mathrm{H}$ ) and the National
Institute of Child Health and Development (to $\mathrm{P} N$ ). $\mathrm{G} \mathrm{Z}$ is a recipient of a 'Fonds pour la Formation de Chercheurs et l'Aide à la Recherche' studentship. G N H is a Scientist of the Medical Research Council of Canada.

(Sequence data from this article have been deposited with the DDBJ/GenBank/EMBL Data libraries under the Accession Nos AF150751, AF150752 and AF150753).

\section{REFERENCES}

Adams T 1995 Differential expression of growth hormone receptor messenger RNA from a second promoter. Molecular and Cellular Endocrinology 108 23-33.

Argetsinger LS \& Carter-Su C 1996 Mechanisms of signalling by the growth hormone receptor. Physiological Reviews $\mathbf{7 6}$ 1089-1107.

Baumbach WR \& Bingham B 1995 One class of growth hormone $(\mathrm{GH})$ receptor and binding protein mRNA in rat liver, GHR1, is sexually dimorphic and regulated by GH. Endocrinology 136 749-760.

Baumgartner JM, Wells CA, Chen CM \& Waters MJ 1994 The role of the WSXWS equivalent motif in growth hormone receptor function. Fournal of Biological Chemistry 269 29094-29101.

Breier BH, Ambler GR, Sauerwein H, Surus A \& Gluckman PD 1994 The induction of hepatic somatotropic receptors after birth in sheep is dependent on parturition-associated mechanisms. Fournal of Endocrinology 141 101-108.

Gluckman PD \& Harding JE 1997 The physiology and pathophysiology of intrauterine growth retardation. Hormone Research 48 (Suppl 1) 11-16.

Hay WW Jr, Catz CS, Grave GD \& Yaffe SJ 1997 Fetal growth: its regulation and disorders. Pediatrics 99 585-591.

Heap D, Lucy MC, Collier RJ, Boyd CK \& Warren WC 1995 Nucleotide sequence of the promoter and first exon of the somatotropin receptor gene in cattle. Fournal of Animal Sciences 731529.

Hill DJ, Riley SC, Bassett NS \& Waters MJ 1992 Localisation of the growth hormone receptor, identified by immunocytochemistry, in second trimester human fetal tissues and in placenta throughout gestation. Fournal of Clinical Endocrinology and Metabolism 75 646-650.

Jansen M, De Moor CH, Sussenbach JS \& van den Brande JL 1995 Translational control of gene expression. Pediatric Research 37 681-686.

Jin CF, Mata M \& Fink DJ 1994 Rapid construction of deleted DNA fragments for use as internal standards in competitive PCR. PCR Methods Applications 43 252-255.

Leung DW, Spencer SA, Cachianes G, Hammonds RG, Collins C, Henzel WJ, Barnard R, Waters MJ \& Wood WI 1987 Growth hormone receptor and serum binding protein: purification, cloning and expression. Nature 330 537-543.

Martini JF, Pezet A, Guezennec YC, Edery M, Postel-Vinay MC \& Kelly PA 1997 Monkey growth hormone (GH) receptor gene expression. Fournal of Biological Chemistry 272 18951-18958.

Menon RK, Stephan DA, Singh M, Morris SM \& Zou L 1995 Cloning of the promoter-regulatory region of the murine growth hormone receptor. Fournal of Biological Chemistry $2708851-8859$

O’Mahoney JV, Brandon MR \& Adams TE 1994 Identification of a liver-specific promoter for the ovine growth hormone receptor. Molecular and Cellular Endocrinology 101 129-139. 
Pausova Z, Morgan K, Fujiwara TM \& Hendy GN 1995 Evolution of a repeat sequence in the parathyroid hormone-related peptide gene in primates. Mammalian Genome 6 408-414.

Pekhletsky RI, Chernov BK \& Rubtsov PM 1992 Variants of the 5 -untranslated sequence of human growth hormone receptor mRNA. Molecular and Cellular Endocrinology 90 103-109.

Rosenbloom AL, Rosenfeld RG \& Guevara-Aguirre J 1997 Growth hormone insensitivity. Pediatric Clinics of North America 44 423-442.

Schnoebelen-Combes S, Louveau I, Postel-Vinay MC \& Bonneau M 1996 Ontogeny of GH receptor and GH-binding protein in the pig. Fournal of Endocrinology 148 249-255.

Simard M, Manthos H, Giaid A, Lefèbvre Y \& Goodyer CG 1996 Ontogeny of growth hormone receptors in human tissues: an immunohistochemical study. Fournal of Clinical Endocrinology and Metabolism 81 3097-3102.

Walker JL, Moats-Staats BM, Stiles AD \& Underwood LE 1992 Tissue-specific developmental regulation of the mRNAs encoding the growth hormone $(\mathrm{GH})$ receptor and the $\mathrm{GH}$ binding protein in rat fetal and postnatal tissues. Pediatric Research 31 335-339.

Wang YD \& Wood WI 1995 Amino acids of the human growth hormone receptor that are required for proliferation and Jak-STAT signaling. Molecular Endocrinology 9 303-311.
Ymer S \& Herington AC 1992 Developmental expression of the growth hormone receptor gene in rabbit tissues. Molecular and Cellular Endocrinology 83 39-49.

Zogopoulos G, Figueiredo RMO, Jenab A, Ali Z, Lefèbvre Y \& Goodyer CG 1996a Expression of exon three retaining and deleted human growth hormone receptor mRNA isoforms during development. Fournal of Clinical Endocrinology and Metabolism 81 775-782.

Zogopoulos G, Albrecht S, Pietsch T, Alpert L, von Schweinitz D, Lefèbvre Y \& Goodyer CG $1996 b$ Fetal- and tumorspecific regulation of growth hormone receptor mRNA expression in human liver. Cancer Research $\mathbf{5 6}$ 2949-2953.

Zogopoulos G, Lerner S, Albrecht S, Pietsch T, Alpert L, von Schweinitz D, Giussani G, Nathanielsz \& Goodyer CG 1997 Regulation of growth hormone receptor (GHR) mRNA in primates. Program of the 79th Annual Meeting of the (US) Endocrine Society, Abstract no. P2-216.

Zogopoulos G, Goodyer CG \& Hendy GN 1998 Cloning and characterization of promoter regions in the human growth hormone receptor gene. Program of the 80th Annual Meeting of the (US) Endocrine Society, Abstract no. $\mathrm{P} 2-251$.

RECEIVED 21 January 1999 